\title{
Laicismo y clericalismo en Córdoba: la batalla por la educación $(1923-1945)^{1}$
}

\section{Laicism and clericalism in Cordoba: the battle for education (1923-1945)}

\author{
César Tcach ${ }^{2}$ \\ Rebeca Camaño Semprini ${ }^{3}$
}

Resumen: En el presente texto nos proponemos analizar las batallas libradas por dominar el campo educativo cordobés entre las décadas del veinte y del cuarenta, entendiéndolas como momentos de una lucha más amplia por la hegemonía cultural en la provincia. La construcción de dicha hegemonía cultural fue un proceso inacabado, producto de la incapacidad para imponerse de los diversos y hasta opuestos proyectos en colisión.

Palabras clave: hegemonía cultural; educación; cultura de la resistencia.

\begin{abstract}
In this text we propose to analyze the battles fought to dominate the educational field of Cordoba between the twenties and the forties, understanding them as moments of a broader struggle for cultural hegemony in the province. The construction of this cultural hegemony was an unfinished process, the product of the inability of diverse and even opposing projects to impose themselves in collision.
\end{abstract}

Keywords: cultural hegemony; education; culture of resistance

\section{Introducción}

El conflicto Estado-Iglesia constituyó uno de los clivajes principales en la formación de los Estados nacionales del mundo occidental (Rokkan, 1971). En el caso argentino, el duelo entre la soberanía estatal y las atribuciones eclesiásticas estuvo presente con sus propias peculiari-

\footnotetext{
1 Trabajo recibido el //2019. Aceptado el 30/06/2019.

${ }^{2}$ Universidad Nacional de Córdoba. Consejo Nacional de Investigaciones Científicas y Técnicas. Contacto: cesartcach@gmail.com

${ }^{3}$ Universidad Nacional de Córdoba. Consejo Nacional de Investigaciones Científicas y Técnicas. Contacto: rebesemprini83@gmail.com
} 
dades en el proceso de consolidación del Estado. Si bien la Iglesia se vio desplazada de diversas funciones que hasta entonces había concentrado, el laicismo secularizador encontró límites en su avance sobre distintas esferas sociales por el poder y la influencia ejercida por la Iglesia Católica.

Su peso en Córdoba llamó la atención de estudiosos argentinos y extranjeros. Desde Sarmiento en su célebre Facundo hasta autores contemporáneos como el historiador norteamericano Richard Morse, pusieron énfasis en contrastar la moderna Buenos Aires, alimentada por Bentham, Rousseau y Montesquieu, con Córdoba, plaza fuerte del realismo monárquico español y el escolasticismo (Morse, 1982). José Aricó (1989) -principal referente intelectual del pensamiento gramsciano en América Latina- aludió a la matriz integrista de la Iglesia cordobesa y el historiador italiano Loris Zanatta (1996) destacó su papel en el proyecto de construcción de una nación homogéneamente católica.

Diversos estudios sobre historia política de Córdoba hicieron referencia útiles a la interpretación del clivaje entre laicismo y clericalismo en distintas coyunturas: la gestación de un proyecto global restrictivo en lo político y dogmático en lo cultural durante la segunda mitad del siglo XIX (Roitenburd, 2000), las luchas entre liberales y católicos en las primeras décadas del siglo XX (Moyano, 2010; Vidal 1995), la incidencia de Acción Católica a partir de los años treinta (Blanco, 2007), el enfrentamiento con el sabattinismo y su incidencia en el derrocamiento de Perón (Ferrero,1984; Tcach, 1991,2006), las relaciones entre los poderes políticos y eclesiásticos en el interior de la provincia (Camaño Semprini, 2017), las tensiones durante el tercer gobierno peronista (Servetto, 1998; Iribarne, 2017), su relación con los usos de la historia en el transcurso la dictadura instaurada en 1976 (Philp, 2009), entre otros aportes significativos. En ellos se advierte, asimismo, la contracara: los destellos de una cultura de resistencia al predominio clerical, desde la tesis doctoral de Ramón J. Cárcano sobre los derechos de los hijos sacrílegos, incestuosos y adulterinos en 1884 (condenada por herética en todas las iglesias de Córdoba) hasta las políticas educativas secularizadoras del gobierno de Obregón Cano y Atilio López en 1973-74, pasando por las experiencias del movimiento de la Reforma Universitaria de 1918, las luchas del movimiento estudiantil y una intelectualidad heterodoxa en las décadas siguientes o los gobiernos radicales laicistas de Amadeo Sabattini, Santiago del Castillo y Justo Páez Molina. Experiencias que, a la postre, tornaron siempre inacabada la hegemonía católica. Ni los pre- 
suntos heresiarcas del laicismo modernizador lograron imponer sus posiciones, ni los clérigos legitimarse en su autoproclamada condición de «directores de almas», uniformizando los valores y conductas de la sociedad cordobesa.

A tenor de lo expuesto, en el presente texto nos proponemos analizar las batallas libradas por dominar el campo educativo cordobés entre la Convención Constituyente de 1923 y los orígenes del peronismo (1943-46) entendiéndolas como momentos de una lucha más amplia por la hegemonía cultural en la provincia. En función de este interés, en este texto se articulan tres momentos claves: el predominio clerical (192336) robustecido tras el golpe militar de 1930, las ofensivas laicistas de los gobiernos radicales (1936-43) legitimadas por la herencia de la Reforma Universitaria en el contexto de la lucha antifascista, y la exitosa contraofensiva clerical que tuvo lugar tras la revolución de junio de 1943.

\section{Predominio conservador y filones de resistencia (1923-1936)}

El clivaje entre liberalismo y clericalismo irrumpió con fuerza en la Convención Constituyente de la provincia de Córdoba que tuvo lugar en 1923 durante la gobernación de Julio A. Roca (h.). Reunida sin la presencia de la UCR -que se había abstenido de participar en las elecciones por considerar ilegítimo al gobierno provincial dado que había sido electo merced a un sistema de circunscripciones electorales que beneficiaba al Partido Demócrata- la posición favorable a la educación popular, gratuita y laica fue sostenida por los siete convencionales socialistas, entre los que se contaban Juan B. Justo (fundador del Partido Socialista) y Nicolás Repetto. Esta postura fue defendida por un maestro: Edmundo Tolosa, quien sostuvo que enseñar religión a los niños era un atentado contra sus aptitudes intelectuales (Chanaguir, 1994, p.175).

Pese a las coincidencias de los socialistas con un sector minoritario de los convencionales demócratas -disidentes con la posición clerical conservadora dominante en su partido- en la convención de 1923 se resolvió incluir siete bases para la reforma de la constitución de la provincia en lo referente a la educación común, que nada decían respecto al carácter laico o religioso de la enseñanza. ${ }^{4}$ La adecuación de la normativa

\footnotetext{
${ }^{4}$ Diario de sesiones de la Honorable Convención Reformadora de la Constitución. Provincia de Córdoba, 1923. Tomo I, p. 139.
} 
educativa al nuevo encuadre provincial, por otra parte, se fue postergando en los años siguientes.

En 1930, el pedagogo Antonio Sobral -perteneciente al sector radical más identificado con las banderas del laicismo, la Reforma Universitaria y el cambio social- presentó en la Cámara de Diputados un proyecto de Ley Orgánica de la Educación Primaria que contenía tres objetivos centrales: poner en práctica una concepción del niño como sujeto activo de la educación y no como mero receptor pasivo de los contenidos dictados por sus maestros, garantizar la libertad de los docentes para ejercitar enfoques pedagógicos modernos y potenciar la participación de los padres en el desarrollo educativo. En su proyecto encontraban ecos filones de pensamiento provenientes de experiencias como las de María Montessori en Italia (con su Casa dei Bambini), Ovidio Decroly en Bélgica, Ángelo Patri en Estados Unidos y de la «Escuela Nueva» promovida por Juan Mantovani, para quien era imperativo reemplazar la escuela informativa y del «saber hecho» por la formativa y del «saber haciéndose» (Calvo, 1972, pp. 5-6). También se nutría de su propia experiencia. En la década de 1920 Sobral había creado un complejo institucional en Villa María integrado por la Biblioteca Bernardino Rivadavia y sus anexos Instituto de Enseñanza Media y Universidad Popular. Entre 1927 y 1937 dio nacimiento al Instituto Secundario Bernardino Rivadavia, a la Escuela de Comercio Joaquín V. González y a la Escuela Normal Víctor Mercante (Roitenburd, 2000, p. 186).

En consonancia con este universo de pensamiento, el proyecto omitía la enseñanza de religión en las escuelas y en su artículo segundo destacaba que la educación primaria debía propender al desarrollo integral de la personalidad del educando, favoreciendo su espontaneidad creadora y la actividad vocacional. En el segundo inciso del artículo séptimo señalaba que la enseñanza incluiría «conocimientos generales e iniciación cultural». ${ }^{5}$ La comisión encargada de su estudio aconsejó agregar detrás de «cultural» las palabras «y moral», así como la redacción de un nuevo artículo, estableciendo que el Consejo General de Educación debería reglamentar el minimum de enseñanza que debía acreditarse y que este no excluiría «la enseñanza religiosa, que se dará por Ministros del Culto Católico, o en su defecto por personas debidamente autorizadas por las autoridades eclesiásticas». ${ }^{6}$

${ }^{5}$ Diario de Sesiones de la Honorable Cámara de Diputados, 1930, p. 21.

${ }^{6}$ Diario de Sesiones de la Honorable Cámara de Diputados, 1930, p. 281. 
Para justificar estas adiciones, el diputado Ángel Cabral, perteneciente a un sector clerical de la UCR, afirmó en el debate correspondiente que, de acuerdo con la organización constitucional de la provincia que, a diferencia de la Nacional, no solo sostenía el culto católico sino que lo adoptaba como su religión oficial-, no podía negarse a los padres de familia católicos el derecho a reclamar para sus hijos la enseñanza de la religión reconocida por el Estado. Asimismo, señalaba que la enseñanza religiosa era obligatoria para el Estado pero no para los educandos, puesto que solo se la prescribía para aquellos niños cuyos padres, tutores o encargados no hubiesen manifestado voluntad en contrario.

Resulta interesante, por otra parte, marcar que -dadas las disidencias presentes en el interior de la comisión encargada de su estudioen su versión original se había propuesto como fórmula conciliatoria una ecuación inversa: que la enseñanza religiosa se limitase a aquellos niños «cuyos padres, tutores o encargados lo solicitasen». Empero, la mayoría se pronunció por el mantenimiento de la fórmula que consagraba la regla general y no la excepción. ${ }^{7}$ Respecto a la novedad que implicaría quitar la enseñanza religiosa de las escuelas -cuya incorporación implicaba para el autor del proyecto «perturbar el desenvolvimiento psicológico de la niñez»- el diputado Cabral se preguntaba si acaso había cambiado tanto el estado moral de Córdoba, que hiciera imposible el mantenimiento de la disposición legal que establecía la ley vigente sobre la enseñanza en Córdoba, interrogante al que respondía con una rotunda negativa. ${ }^{8}$

Para el diario católico Los Principios, no había lugar a dudas: «en un estado que tiene una religión oficial, las escuelas deben enseñar esa religión». ${ }^{9}$ En el interior de los partidos políticos, tanto la UCR como el PD vieron emerger posiciones enfrentadas ante el proyecto de ley. El hecho que Sobral y Cabral, pertenecieran ambos a las filas del radicalismo y que uno de los grandes defensores de la versión original del proyecto fuera el demócrata Alonso, ponía de relieve la transversalidad del clivaje entre laicismo y clericalismo ${ }^{10}$.El proyecto de Sobral fue aprobado por la Cámara de Diputados en agosto de 1930 por unanimidad, a excepción del articulado que la neutralidad estatal en materia religiosa. ${ }^{11}$

\footnotetext{
${ }^{7}$ Diario de Sesiones de la Honorable Cámara de Diputados, 1930, p. 292.

${ }^{8}$ Diario de Sesiones de la Honorable Cámara de Diputados, 1930, p. 294.

${ }^{9}$ Los Principios, 18/08/1930.

${ }^{10}$ Los Principios, 12/08/1930. También consultar Roitenburd (2000, pp. 205-209).

${ }^{11}$ Catorce diputados (once radicales y tres demócratas) votaron a favor de la incorporación
} 
En estas circunstancias, Sobral sostuvo que lo resuelto significaba dejar públicamente de manifiesto ante el país «que nos ha faltado un poco de comprensión educacional, no restándonos nada más que esperar una oportunidad, que no ha de estar lejana (...) para que sea eliminada la disposición que hoy se incorpora, en nombre de los grandes principios que informan la pedagogía y nuestra tradición liberal». ${ }^{12}$ El golpe de Estado de septiembre de 1930, empero, clausuró la posibilidad de realizar avances en el camino de una enseñanza más moderna y laica. Las manifestaciones civiles a favor del general Uriburu estuvieron marcadas por la presencia de la Iglesia Católica: las campanas de la Basílica de Santo Domingo (sita entre avenida Vélez Sarsfield y calle Deán Funes) fueron echadas al vuelo en señal de algarabía y, según la prensa católica, desde los balcones del Obispado monseñor Pablo Cabrera «vertió lágrimas de emoción y entusiasmo» al saludar a los civiles que celebraban en las calles el golpe militar. ${ }^{13}$ Lisardo Novillo Saravia - pocos meses después designado presidente de Acción Católica en Córdoba- encabezó la bienvenida al interventor federal Carlos Ibarguren, intelectual del nacionalismo de derecha y admirador del fascismo: «Señor interventor: estáis en vuestra casa, estáis en Córdoba», sostuvo al recibirlo. ${ }^{14} \mathrm{El}$ lustro que siguió estuvo marcado por el fortalecimiento político de la Iglesia: a la constitución de Acción Católica en 1931 (llamada «pupila de nuestros ojos» al decir del papa Pío XI), le siguió la primera Asamblea Federal de Hombres Católicos (1933), la conversión del Obispado en Arzobispado (1934), la creación del Obispado de Río Cuarto ese mismo año y la creciente confesionalización del espacio público. Así, por ejemplo, en Carlos Paz, la cruz colocada en la montaña conocida como Cerro de la Cruz, y en Río Ceballos el Cristo de NuPorá, datan de las postrimerías del gobierno conservador, entre 1935 y 1936.

de la enseñanza religiosa y siete (cuatro radicales y tres demócratas) lo hicieron en contra. Los Principios, 20/08/1930.En este punto cabe recordar queel Poder Ejecutivo provincial (en manos de los sectores más conservadores del radicalismo), al ser interpelado por la Cámara, se pronunció a favor del mantenimiento de las disposiciones legales en vigencia, o sea, porque se reconozca en el programa mínimo de enseñanza primaria la instrucción religiosa. ${ }^{12}$ Diario de Sesiones de la Honorable Cámara de Diputados, 1930, p. 290.

${ }^{13}$ Los Principios, 10/09/1930.

${ }^{14}$ La Voz del Interior, 19/09/1930; Los Principios, 19/09/1930. Véase también Tcach (2010). 


\section{La ofensiva laicista durante el gobierno de Amadeo Sabattini (1936- 40)}

En mayo de 1936, al asumir como gobernador de la provincia de Córdoba, Amadeo Sabattini juró (como lo había hecho en 1922 en su condición de elector presidencial y en 1928 al ser nombrado ministro de Gobierno) por la Patria y el Honor, pero con un añadido de su propia cosecha que hirió aún más la sensibilidad eclesiástica: dijo que se comprometía a proteger y respetar la religión católica porque la constitución se lo ordenaba. El Ejército estuvo ausente en la ceremonia de transmisión del mando y, por consiguiente, no se rindieron los honores de práctica al nuevo gobernador; tampoco se hizo presente el arzobispo de la provincia, Fermín Laffite (Tcach, 1999). Una luz roja se encendió en la Iglesia Católica de Córdoba. Ese mismo mes quedó constituida la Federación de Maestros Católicos, bajo la advocación de «los salvadores principios de Dios, Patria y Familia». ${ }^{15}$ La organización de los docentes católicos apuntaba a conjurar el fantasma que comenzó a corporizarse en agosto de ese año: los radicales sabattinistas presentaron ante la Legislatura provincial -de la mano del diputado Reginaldo Manubens Calvet- un proyecto de Ley Orgánica de Educación Común que compartía los lineamientos generales con la propuesta presentada en 1930 por Sobral. Pero, dando un paso más allá, afirmaba explícitamente que ésta debía ser laica.

El primero en reaccionar fue el obispo de Río Cuarto, Leopoldo Buteler, quien sostuvo en una Pastoral de corte fundamentalista: «La religión ha de ser el punto central de la educación, el elemento unificador de la cultura, la trama de hilos de oro que enlace todas las materias». ${ }^{16}$ El 30 de septiembre de 1936 una carta pastoral conjunta del arzobispo de Córdoba, Fermín Lafitte y del obispo Buteler, sostuvo que la enseñanza laica era «un primer y seguro paso hacia el comunismo» que daba lugar a «generaciones ateas, inmorales y rebeldes (...) como todas las herejías, el arrianismo, el protestantismo,el jansenismo, así también el laicismo es a la vez una doctrina y un partido. Su dogma capital es (...) la negación de toda autoridad religiosa exterior a la conciencia individual, la negación de la Iglesia en cuanto gobierno de las almas». ${ }^{17}$ Des-

\footnotetext{
${ }^{15}$ La Voz del Interior, 30/05/1936.

${ }^{16}$ Los Principios, 05/09/1936.

${ }^{17}$ Los Principios, 03/10/1936.
} 
de la mirada de las pastorales, la enseñanza laica era una pócima tóxica que llevaba a la inmoralidad, la anomia y, eventualmente, al suicidio de la patria. La voz de los prelados - propagada puertas adentro a través del Boletín Eclesiástico de la Arquidiócesis de Córdoba- no quedó relegada al clero provincial sino que este debía difundirla a partir de su discusión en los centros de Acción Católica, la lectura en las misas dominicales y a través de las páginas de la prensa católica.

La asociación entre liberalismo y comunismo así como la estigmatización de los disidentes como «herejes», en el contexto del impacto de la guerra civil española, dio lugar a un editorial del diario $\mathrm{La} \mathrm{Voz} \mathrm{del}$ Interior que advertía: la Iglesia «en cierto modo se ha enrolado en el movimiento fascistizante que amenaza horas dolorosas y amargas para la nación». ${ }^{18}$ La batalla por la educación emprendida por sectores laicos, liberales y socialistas de Córdoba se tradujo en la realización del Primer Congreso de Maestros de la Provincia de Córdoba, celebrado en el Teatro Rivera Indarte, concedido por el gobierno de la provincia. De este modo, se trataba de poner en jaque la incidencia de la Iglesia sobre maestros y profesores. El diario clerical describió el congreso de los docentes en términos no exentos de matices antisemitas: se veía a «los delegados rusos y judíos confraternizando con nuestros vanguardistas criollos y los delegados de algunos sindicatos de obreros, mientras que en las plateas y gallinero se gritaba iMueran los gobiernos burgueses! iAbajo la guerra! y iAbajo la enseñanza religiosa!». ${ }^{19}$

La reacción clerical en Córdoba fue acompañada por el ministro de Justicia e Instrucción Pública de la Nación, Jorge de la Torre, abogado cordobés vinculado a los sectores más conservadores. Al respecto, se denunciaba «la sistemática persecución de profesores y alumnos de colegios nacionales que se tradujo en la prohibición de los centros de estudiantes, la expulsión del vicerrector y varios alumnos del colegio nacional de Río Cuarto, así como severas sanciones a estudiantes secundarios que editaban una revista en el colegio Monserrat de la ciudad de Córdoba. ${ }^{20}$

Ciertamente, el proyecto educativo del sabattinismo cordobés se situaba a contraviento de la oleada clerical-conservadora que se hacía sentir en todo el país. Un año antes, la Intervención Federal a Santa Fe

\footnotetext{
${ }^{18} \mathrm{La} \mathrm{Voz} \mathrm{del} \mathrm{Interior,} \mathrm{11/10/1936.}$

${ }^{19}$ Los Principios, 28/02/1937.

${ }^{20} \mathrm{La} \mathrm{Voz} \mathrm{del} \mathrm{Interior,} \mathrm{25/10/1936.}$
} 
había puesto fin a la experiencia de la ley de enseñanza laica que había estado vigente entre 1934 y $1935 . .^{21}$ En Catamarca, otro interventor federal impuso por decreto la enseñanza religiosa, confiando al Consejo Provincial de Educación la reglamentación de la misma de acuerdo con el obispo de la diócesis local (Zanatta, 2005). En Buenos Aires, el gobierno conservador y fraudulento de Manuel Fresco -cuyo poderío se basaba en el uso aceitado del fraude electoral y un aparato político en el que se combinaban el mundo del delito y la corrupción organizada (Macor, 2001)- dictó por decreto la enseñanza religiosa.

Los Principios resaltaba que mientras esto ocurría en otras latitudes, en Córdoba - provincia «católica por excelencia»- se había presentado en su Legislatura un proyecto de Ley de Educación Común que imponía «contra razón y derecho, la enseñanza laica». Desde esta perspectiva, la provincia también era una «isla», pero no democrática sino presa de un gobierno que, contra la corriente predominante en el país, aún hacía de los principios liberales el norte de su proyecto educativo. ${ }^{22}$ Resulta importante remarcar que para los sectores más conservadores de Córdoba la ejemplaridad del caso bonaerense no se limitaba al aspecto educacional sino que su vida política era permanentemente contrastada con la propia, mostrándola como modelo de orden y disciplina frente al «clima subversivo» que se vivía en la provincia mediterránea.

En noviembre de 1936, la ruptura de relaciones del Senado -en manos del Partido Demócrata- con el Poder Ejecutivo provincial (fundamentado entre otras cosas por el juramento laico y por ende inconstitucional del gobernador), tornó superfluo el tratamiento del proyecto en la Legislatura (Tcach 2017, p.223). Fracasado el intento de reforma educacional por la vía legislativa se procedió a avanzar en ese camino a través de la modificación de los reglamentos educativos. El 23 de junio de 1937, un editorial del matutino católico titulado «El Consejo de Educación desencadena la persecución religiosa» acusaba a ese organismo de esta formado por ateos y denunciaba cuatro de sus recientes resoluciones, a saber: 1) Se quitaron los permisos para enseñanza de religión los días domingos en las sedes de los colegios provinciales, so pretexto que habiendo iglesias en las cercanías podía impartirse en ellas; 2) Se prohi-

\footnotetext{
${ }^{21}$ Tal como lo ha demostrado Diego Mauro (2009), contrariamente a la visión generalizada de Santa Fe como un «feudo liberal», en realidad la enseñanza de religión fue una constante en la provincia desde 1886 y, a rigor de verdad, lo excepcional fue más bien la vigencia de una ley de educación laica durante solamente un bienio.

${ }^{22}$ Los Principios, 10/09/1936.
} 
bió a maestros y alumnos encaminarse en grupo para asistir a ceremonias religiosas; 3) Se prohibió ostentar distintivos religiosos de cualquier índole en el interior de los colegios; 4) Tampoco se bendecirían las banderas de las escuelas; 5) Se dispuso que las nuevas escuelas fundadas bajo la égida del gobierno provincial no fueran bendecidas, rompiendo la tradición por la que se bendecían los edificios escolares; 6) Se prohibió hablar de religión fuera de las «clases especiales» dedicadas a su estudio; 7) A efectos de evitar presiones sobre los niños, se prohibió a los maestros de las escuelas dar clases de religión en ningún grado de la misma escuela, aunque sea en distinto turno (Camaño Semprini, 2017). A estos siete aspectos habría que añadir que las clases de religión se limitaban a media hora semanal y, en muchos casos, como lo denunció el Obispo de Río Cuarto, Leopoldo Buteler, eran ubicadas en los últimos minutos del horario escolar, cuando los niños estaban cansados y solo deseaban regresar a su hogar. En el contexto descripto, el matutino católico sostenía que «desde el Consejo de Educación se había desencadenado «la más impetuosa ofensiva contra la Iglesia» y pedía que «la persecución termine». ${ }^{23}$ En rigor, la revolución educativa que no pudo concretarse vía legislativa se intentaba llevar adelante por vía de cambios reglamentarios.

Los nuevos aires educativos llegaban los más diversos rincones de la provincia. Así, otro editorial de Los Principios condenaba a un maestro de un colegio de la pequeña ciudad de Río Tercero, en el interior provincial, por enseñar la teoría de la evolución de las especies. En tono sarcástico explicaba: «Hace un tiempo, casi un siglo, un naturalista y fisiólogo inglés, después de contemplarse al espejo, concibió una famosa teoría: el hombre desciende del mono». Afirmaba que la ciencia había dejado de lado sus teoría, pero que en Río Tercero, «en pleno agro cordobés, ha aparecido un darwinista (...) es además maestro de escuela y dicta sus clases en un aula de la escuela provincial del pueblo. Y entre las cosas que enseña a sus alumnos figura esta: el hombre desciende del mono». Responsabilizaba por ello al Consejo de Educación del gobierno de Sabattini, partidario de la «escuela neutra», quien ha declarado su prescindencia en el caso. El indignado editorial preguntaba en modo irónico: «¿Cómo se entiende? ¿Prescindencia y se dictan clases de transformismo?». A su juicio se trataba de un verdadero agravio a la ley y a la misma dignidad de la naturaleza humana. ${ }^{24}$ Pero el gobierno de Sabattini se mantuvo

${ }^{23}$ Los Principios, 23/06/1937.

${ }^{24}$ Los Principios, 18/06/1937. 
firme en sus propósitos orientados a la renovación pedagógica. A partir de marzo de 1939, comenzó a transmitirse por LV3 Radio Córdoba, «La hora escolar», programa del Consejo de Educación de la provincia (Díaz 1997, p. 47). En octubre de ese año, un editorial del diario del Arzobispado expresaba, a modo de balance del gobierno de Sabattini, que se había caracterizado por un «ateísmo agresivo» y advertía que se hallaba en la Legislatura provincial un proyecto de ley favorable al «total laicismo en la enseñanza», razón por la cual se le reclamaba al Partido Demócrata que se definiera contra esa iniciativa. ${ }^{25}$

\section{La ofensiva laicista durante el gobierno de Santiago del Castillo (1940-43)}

Un día antes de las elecciones a gobernador de 1940 que dieron el triunfo a Santiago del Castillo -quien había sido promovido por Amadeo Sabattini para sustituirlo al terminar su mandato- el diario del Arzobispado difundió las «Normas del Episcopado Argentino que debe observar el elector católico»: «para oponer un dique al avance funesto del laicismo $(. .$.$) en nuestro oficio de directores de almas y jefes espiri-$ tuales del pueblo católico» llamaban a votar por quienes procuren el mayor bien de la religión aunque no pertenezcan al propio partido. En el ítem IV añadía que ningún católico podía votar por quienes al asumir sus cargos violaran el juramento religioso, propiciaran el laicismo escolar y el divorcio legal. ${ }^{26}$ La mayoría de los cordobeses, empero, optó por votar al radicalismo sabattinista.

El gobierno de Santiago del Castillo promovió la ampliación de la enseñanza mixta, ya presente en algunas instituciones de la provincia, a la que el diario católico Los Principios le dedicó varias y sustanciosas editoriales condenatorias. ${ }^{27}$ Pese a la presión ejercida por los sectores clericales, la enseñanza mixta, fue sostenida. En agosto de 1940 Santiago del Castillo envió a la Legislatura su proyecto de ley de educación, en el que se establecía que la escuela primaria sería mixta hasta el cuarto grado inclusive. En su presentación, el Ejecutivo provincial retomaba explícita-

\footnotetext{
${ }^{25}$ Los Principios, 17/10/1939.

${ }^{26}$ Los Principios, 09/03/1940.

${ }^{27}$ Los Principios, 11/04/1940; 12/04/1940; 13/04/1940; 14/04/1940; 29/04/1940; 08/ 05/1940; 11/05/1940;20/05/1940.
} 
mente los antecedentes de Sobral y Manubens Calvet y postulaba que, de aprobarse, el nuevo proyecto le imprimiría a la educación primaria de la provincia nuevos rumbos. En ese mismo mes, se fundó la Escuela Mixta Domingo Cabred (diferencial).

Tal como ha señalado Roitenburd (2000) la polémica no solo giraba en torno a la enseñanza religiosa sino que se extendía a los problemas de la pedagogía democrática, la investigación y la libertad de acceso a la cultura universal. Remitía, en este sentido, a la bifurcación entre dos corrientes normalistas, una «normalizadora», autoritaria, reacia al desarrollo de la espontaneidad infantil, el juicio crítico y el debate creativo; y, otra, que asumía las raíces normalistas pero a la luz de las tendencias de la «escuela nueva» o «escuela activa», portadora de un laicismo tolerante, una apertura a la ciencia y un patriotismo ciudadano en diálogo con la cultura universal.

Una vez más, el Episcopado cordobés intervino como cuerpo ante las autoridades provinciales para intentar frenar la sanción del proyecto educativo del gobierno radical. Fermín Lafitte y Leopoldo Buteler visitaron al gobernador y le entregaron un minucioso memorial. Posteriormente, se entrevistaron con el presidente de la Cámara de Diputados, Hércules Baggini. En sus discursos existía una completa homologación entre la Nación argentina y la religión católica, lo cual adquiría una particular relevancia en Córdoba donde -de acuerdo con Roitenburd (2000)puede reconocerse la construcción histórica de una imagen del espacio provincial como depositario de una «verdadera tradición nacional» simbiótica de la religión católica en oposición al cosmopolitismo porteño. La reacción eclesiástica fue acompañada de la movilización de una miríada de organizaciones católicas construidas bajo su amparo, como Acción Católica, la Federación de Maestros y Profesores Católicos o la Sociedad del Divino Maestro. ${ }^{28}$ Finalmente, como había ocurrido en 1936, el debate se pospuso indefinidamente y, a la postre, nunca se realizó, pese a que en 1942 el gobierno provincial volvió a insistir ante la Legislatura para que el proyecto fuera tratado y aprobado. ${ }^{29}$

La ofensiva laicista y modernizadora, empero, incluía un abanico amplio de políticas renovadoras que se implementó independientemente del bloqueo legislativo. En julio de 1940, inspirándose en el ejemplo de las experiencias educativas de la República Española (entre 1931-36)

${ }^{28}$ Los Principios, 13/09/1942.

${ }^{29}$ Diario de Sesiones de la Honorable Cámara de Diputados, 1942, p. 946. 
orientadas a la educación popular, el Consejo de Educación aprobó las «Misiones Pedagógicas», dirigiéndose una a los departamentos del norte provincial y otras hacia los del sur. Asimismo, comenzó a discutirse -por iniciativa de Julio Bernardo Serebrinsky- la creación de un instituto que centrase su atención en la orientación vocacional de los alumnos, aspecto que constituía una verdadera avanzada pedagógica (Díaz, 1997).

En junio de 1941, el Ejecutivo provincial promovió la presentación de un proyecto en la Legislatura para la creación de una Escuela Normal Provincial provisto de un Instituto Pedagógico, orientado a la investigación e innovación educativa. Se pretendía que éste actuara como «centro de creación, formación e irradiación de la cultura en materia educativa» y que actuara «en una constante obra de reactualización docente y cultural» para evitar «aletargamientos espirituales que al mantener alejados a los docentes de las nuevas corrientes del pensamiento pedagógico» que generan «funestas consecuencias en la formación cultural de los educandos». ${ }^{30}$ Se buscaba, que el instituto desarrollara experiencias pedagógicas e indagaciones científicas que permitieran realizar aportes originales en el ámbito de las ciencias de la educación. El proyecto fue aprobado en septiembre de 1941, a pesar de las críticas del diario del Arzobispado. Y, más aún, el reconocido pedagogo Saúl Taborda -referente intelectual de los estudiantes que protagonizaron la Reforma Universitaria en 1918- fue nombrado como su primer director.

Cabe añadir que al fundamentar la necesidad de la creación de la Escuela Normal, el Poder Ejecutivo provincial invocó el principio federalista de la Constitución Nacional y postulaba que éste no podía restringirse a lo político y económico-financiero sino que también debía abarcar el aspecto cultural, por lo que «Córdoba, sin desdeñar por cierto la obra de la Nación en esta materia, necesita y debe realizar una formación especial para sus docentes, que responda a sus exigencias regionales y que facilite la realización de su política reformista de la educación». ${ }^{31}$ El proyecto educativo del sabattinismo, pues, subrayaba la importancia del vínculo con la región y las necesidades sociales en el orden local. En consonancia con esta perspectiva, el Consejo de Educación creó la Biblioteca Infantil y fomentó la publicación de libros de texto con fuerte contenido local y regional, con el fin de acompañar la reforma de los

\footnotetext{
${ }^{30}$ Los Principios, 13/06/1941.

${ }^{31}$ Biblioteca de la Legislatura de la provincia de Córdoba, Honorable Cámara de Diputados, Diario de Sesiones, 1941, p. 214.
} 
contenidos en los planes de estudio (Díaz 1997, pp. 61-62). Su base conceptual -la concepción del niño y del adolescente como seres activos cuya capacidad de creación debía ser promovida- se encontraba en las antípodas de los criterios dogmáticos y sacralizados defendidos por la Iglesia Católica.

En abril de 1943 el clericalismo cordobés sufrió un nuevo golpe: el gobernador designó a Antonio Sobral (el intelectual que había promovido el frustrado de reforma educativa en 1930), como presidente del Consejo de Educación de la provincia de Córdoba. Poco tiempo después, este organismo aprobó un Estatuto del Magisterio -sancionado luego por decreto del Poder Ejecutivo- que preveía concursos para el acceso a la docencia. Su artículo 40 garantizaba la libertad de pensamiento de los docentes, tanto en el plano político ideológico como en el filosófico y religioso. Explícitamente sostenía que las ideas de los profesores «no podrán ser causal de sanciones disciplinarias de ninguna índole» (Diaz 1997, p.65). Asimismo, prohibía el proselitismo religioso o político de los docentes. De esta manera, se apuntaba a dos objetivos: eliminar la posibilidad de la discriminación ideológica de los docentes a la que era tan las autoridades escolares vinculadas a la Iglesia (apuntalando la estabilidad laboral) y erigir un veto a la propaganda religiosa en los colegios privados católicos.

\section{Dictadura militar y contra-ofensiva católica (1943-46)}

«Hay que remover toda esa hojarasca pedagógica impuesta por una torpe conciencia normalista y volver a la formación del niño por el abandonado camino que le habla más a su alma», sostenía un editorial del matutino católico Los Principios dos días después del golpe militar de junio de 1943 (Tcach 2017). ${ }^{32}$ En rigor, las páginas del diario del Arzobispado se vieron plagadas de editoriales que reclamaban no solo por la efectivización de la enseñanza católica en las escuelas sino también por la reforma de los planes de estudios puestos en vigencia por el sabattinismo y la remoción del personal que se consideraba izquierdista o izquierdizante. Asimismo, se pregonaba la anulación de las escuelas mixtas y se reclamaba «impregnar de la verdad divina el conjunto total de enseñan-

\footnotetext{
${ }^{32}$ Editorial de Los Principios,06/05/1943.
} 
za, el espíritu de los docentes y de los programas, y la acción de las autoridades que la dirigen». ${ }^{33}$

En consonancia con ello, las jerarquías eclesiásticas reclamaban la remoción del presidente del Consejo de Educación, Antonio Sobral, quien -en tanto «herencia del gobierno depuesto»- constituía un obstáculo insalvable para la implantación efectiva de la enseñanza religiosa en las escuelas provinciales. Con este reclamo la Iglesia cordobesa pretendía demostrar -en palabras textuales- «que si sabemos enseñar a rezar, sabemos también luchar en defensa de nuestros más sagrados derechos». ${ }^{34}$ Las implicancias políticas de esta afirmación son elocuentes, no solo se pretendía enseñar el catolicismo, sino instruir férreos defensores del orden social propugnado por la Iglesia.

Las presiones ejercidas por la prensa y las autoridades católicas surtieron efecto, pues poco después se decidió la intervención del Consejo Provincial de Educación, con el consecuente desplazamiento de las autoridades nombradas por el sabattinismo y el reemplazo de Sobral en la presidencia por el Coronel (R) Carlos Adinet. El pedagogo Saúl Taborda fue forzado a renunciar como director del Instituto Pedagógico. Una de las medidas más importantes -por su alto contenido simbólicotomadas por las flamantes autoridades fue la disposición de que fuera colocado un crucifijo en cada escuela de la provincia. Este fue el primero de una serie de análogos decretos, emanados en todo el país (Zanatta, 1999) y contó con el inmediato aplauso de la jerarquía eclesiástica, la prensa católica y el laicado de Córdoba. A las editoriales elogiosas de Los Principios se sumaron las notas de agradecimiento de la Acción Católica y del Arzobispado. ${ }^{35}$

Poco después se produjo la tan anhelada culminación del proceso iniciado en junio de 1943 y augurado con ahínco durante los meses siguientes: el ingreso de Cristo «a la escuela de Córdoba y a toda la escuela argentina, con todos los derechos». ${ }^{36}$ En efecto, el 31 de diciembre de 1943 fue reintroducida la enseñanza religiosa en las escuelas públicas del país. Como respuesta a esta medida «el mundo católico y el Episcopado (...) levantaban un coro jubiloso y celebraban la apoteosis del triunfo» (Zanatta, 1999, p. 110).

\footnotetext{
${ }^{33}$ Los Principios, 03/07/1943.

${ }^{34}$ Los Principios, 25/07/1943

${ }^{35}$ Los Principios, 19/11/1943 y 23/11/1943.

${ }^{36}$ Los Principios, 18/11/1943.
} 
Desde su perspectiva, no se trataba de una regalía concedida por el gobierno a la Iglesia, sino una restauración de su derecho divino a educar. Las razones que esbozaban para argumentar su interpretación remitían a distintos ejes del mito de la Nación católica: la identificación entre argentinidad y catolicismo, la concepción del catolicismo como baluarte de la independencia y la soberanía nacionales y una relectura confesional de la Constitución. Se consideraba que hasta entonces el sistema educativo había sido sustancialmente totalitario, en virtud de la influencia de doctrinas extrañas a la identidad nacional» (Zanatta, 1999, p. 113).

En el caso cordobés, la situación previa adquiría un cariz particular por la tónica laicista impuesta por el sabattinismo. Al respecto, Los Principios aseguraba que durante sus gobiernos se había procedido como si las disposiciones constitucionales no existieran, violándolas abiertamente al poner dificultades para la enseñanza de la religión. Se argüía, consecuentemente, que dichas gestiones habían sido «las más nefastas que ha tenido la Provincia», por lo que las autoridades actuales no estaban sino limitándose a «restaurar la legalidad perdida». ${ }^{37}$

En febrero de 1944, el decreto 4608, firmado Manuel Augusto Ferrer -ministro de Gobierno e Instrucción Pública en ejercicio de la gobernación-derogó la enseñanza mixta: se explicitó que la decisión tomada obedecía a dos motivos: la educación mixta atentaba contra la «doctrina clásica cristiana» y en consonancia con lo sostenido por el papa Pio $\mathrm{XI}$, que había calificado de «deplorable confusión el principio de coeducación», convertía en»promiscua la legítima sociedad humana».y en segundo lugar, porquela escuela mixta carecía de «arraigo en nuestra tradición escolar». ${ }^{38}$ Simultáneamente se avanzaba sobre otro de los baluartes de la escuela sabattinista: los programas educativos. Se argumentaba que era necesaria una simplificación general de éstos «conforme a los principios de la sana pedagogía y a las exigencias de la formación integral de los educandos». Ello implicaba, por una parte, despojarlos de «la información frondosa y enciclopédica que los caracteriza»y, por la otra, la incorporación de la enseñanza religiosa como materia de estudio, sujeta al mismo régimen de calificaciones que el resto de las asignaturas. ${ }^{39}$ Se ponía fin así al escolanovismo ensayado por la experiencia sabattinista. Simbólicamente, esto quedó sellado con la entroni-

\footnotetext{
${ }^{37}$ Los Principios, 13/04/1944.

${ }^{38}$ Ministerio de Gobierno, Tomo 83 (1944), folios 49-50 (2-2-1944).

${ }^{39}$ Los Principios, 08/02/1944.
} 
zación de un crucifijo en la sededel Consejo de Educación de la Provincia, en noviembre de 1944.

El 5 de abril de 1945 la Asociación de Maestros de la provincia de Córdoba (cuya sede estaba en calle Santa Fe 238), presidida por Otto González presentó una nota al interventor federal Juan Carlos Díaz Cisneros. Criticaba la suspensión del Estatuto del Maestro y la derogación del decreto reglamentario de ingreso a la docencia: «los favorecidos con nombramientos y ascensos se reclutan casi en su totalidad, entre los adherentes y simpatizantes a organizaciones confesionales». Además, denunciaba esta organización gremial, los maestros «tenidos por liberales y democráticos» eran sancionados con medidas disciplinarias. ${ }^{40}$

\section{Reflexiones finales}

La batalla por la educación entre laicistas modernizadores y clericales conservadores fue un capítulo central de un combate más amplio que trascendía el plano educativo. Constituyó el punto axial a partir del cual un amplio sector de la sociedad cordobesa - partidos políticos, organizaciones gremiales, intelectuales y gobiernos progresistas- puso en tela de juicio las tradiciones, los valores y códigos dominantes en el plano de la cultura. La educación, pues, fue el terreno privilegiado en el cual se libraba la lucha por la hegemonía cultural.

De lo narrado en estas páginas, se imponen dos conclusiones de relevancia en el largo plazo histórico. La primera, remite a la siempre inacabada construcción de la hegemonía católica en Córdoba. El sueño eclesial de convertirla en la Roma de América del Sur nunca terminó de convertirse en realidad. Los empeños uniformizadores de la Iglesia se vieron entorpecidos en cada coyuntura por la influencia de sectores laicos del radicalismo y, en menor medida, del Partido Demócrata, por los partidos de izquierda y las organizaciones que se desarrollaron bajo su influjo, por intelectuales disidentes y educadores imbuidos de las nuevas corrientes pedagógicas e, inclusive, por gobiernos provinciales que operaron con autonomía con respecto a las directivas eclesiásticas. En otras palabras -y esta es la segunda conclusión- el papel de «directores de almas» que se arrojaban los sacerdotes católicos y sus jerarquías institucionales chocó siempre con una cultura de resistencia que -en el período

\footnotetext{
${ }^{40}$ M. de Gobierno - 1945 Tomo 1. Asociaciones-Centros.
} 
analizado- se nutrió del universo de valores que emergió del movimiento de la Reforma Universitaria de 1918, en el que se combinaba de modo heterodoxo, liberalismo, radicalismo laicista y socialismo entre sus vetas más destacadas.

La expresión «cultura de resistencia», supone la imposibilidad tanto de imponerse como de disolverse. Carece de fuerza para la imposición pero tiene un entramado cuya densidad la exime del agotamiento. Como sostuvo José Aricó en su célebre texto sobre tradición y modernidad en la sociedad cordobesa: «El confesionalismo católico, basado en la fuerte presencia de una Iglesia de matriz ideológica integrista, debió enfrentarse siempre con el obstáculo que le ofrecía un radicalismo laico persistente» (Aricó 1989, p. 11). Radicalizar la democracia, implicaba una vocación emancipatoria que -ya sea en sus vertientes liberales, socialistas o masonas- conducía a la desobediencia de los mandatos tradicionales. Pero esta cultura de resistencia, era también en gran medida, «una cultura de lo imposible» (Marimón 1989), capaz de erosionar dogmas y esencialismos, aunque infructuosa para convertirse en hegemónica.

Entre 1923 y 1945, los principales actores de esta lucha se enfrentaron encarnizadamente y soñaron con imponerse. El catolicismo clerical, estimulado por el auge de las derechas europeas y las directivas vaticanas de Pio XI y Pio XII; los reformadores laicos por el sueño de un cambio social que oscilaba entre la reforma radical y la revolución social. Ambos experimentaron, sin embargo, triunfos y derrotas parciales. Los conservadores se impusieron en 1923, fueron amenazados por iniciativas legislativas en 1930 y emergieron triunfantes tras el golpe militar de ese año; los progresistas pasaron a la ofensiva entre 1936-43 y limitaron el poder de la Iglesia (en contraste con lo que ocurría a nivel nacional), para ver luego truncadas sus conquistas tras el golpe de junio de 1943. Pero su humus cultural volvería a emerger una y otra vez en las décadas siguientes. En ambos casos, la imposibilidad de liquidar el peso del contendiente en los valores y códigos sociales, permite pensar, entonces, en la inacabada construcción de la hegemonía católica o bien en una suerte de empate hegemónico inestable marcado por la asimetría entre el poder de la Iglesia y las impugnaciones de sus cuestionadores. 


\section{Referencias bibliográficas}

Aricó, J. (1989). Tradición y modernidad en la cultura cordobesa. Plural, (13), 10-14.

Blanco, J. (2007). Religión y espacio público en la Argentina moderna. El caso de la Acción Católica Argentina en Vidal, G. (Comp.).La politica y la gente. Estudios sobre modernidad y espacio público. Córdoba, 1880-1960. Córdoba, Argentina: Ferreyra.

Calvo, B. (1972). Pensamiento vivo del doctor Antonio Sobral. Villa María, Argentina: Opinión.

Camaño Semprini, R. (2017). Entre el sabattinismo y el peronismo: representaciones, prácticas y proyección politica del obispado de Leopoldo Buteler (Rio Cuarto, 1935-1955). Tesis de Doctorado en Historia. Universidad Nacional de Córdoba. Córdoba, Argentina.

Camaño Semprini, Rebeca. (2017). Entre el sabattinismo y el peronismo: representaciones, prácticas y proyección politica del Obispado de Leopoldo Buteler (Rio Cuarto, 1934-1955) (Tesis de Doctorado). Facultad de Filosofía y Humanidades de la Universidad de Córdoba, Córdoba, Argentina.

Chanaguir, E. (1994). El Partido Socialista y la Convención Reformadora de la provincia de Córdoba de 1923. Estudios, (3), 157-180.

Díaz, S. (1997). La escuela estatal primaria y normal de Córdoba 19361943. En La Educación en Córdoba. Siglo XX, tomo 1, Córdoba, Argentina: Fundación Amadeo Sabattini.

Ferrero, R. (1984). Sabattini y la decadencia del Trigoyenismo. Buenoa Aires, Argentina: Centro Editor de América Latina.

Iribarne, M. (2017). El diario del Arzobispado en la Córdoba peronista. De la victoria al golpe de Estado de 1976.. Córdoba, Argentina: Universidad Nacional de Córdoba.

Macor, D. (2001). Partidos, coaliciones y sistema de poder, en Cattaruzza, A. (Dir.), Nueva Historia Argentina, Tomo VII: Crisis económica y avance del Estado e incertidumbre política (1930-1943), pp. 49-95. Buenos Aires, Argentina: Sudamericana.

Marimón, A. (1989). La cultura de lo imposible. Plural, (13), 4-9.

Mauro, D. (2009) Catolicismo, educación y política. La enseñanza religiosa entre la curia diocesana y las orientaciones educativas del 
estado provincial. Santa Fe, 1915-1937. Estudios Sociales, (36), 143172.

Morse, R. (1982). El espejo de Próspero. México, México: Siglo XXI.

Moyano, J. (2010). El clivaje entre clericales y liberales en la política cordobesa entre 1890 y 1930 en Tcach, C. (Coord.). Córdoba bicentenaria. Claves de su historia contemporánea, pp. 113-133. Córdoba, Argentina: Universidad Nacional de Córdoba.

Philp, M. (2009). Memoria y politica en la historia argentina reciente: una lectura desde Córdoba. Córdoba, Argentina: Universidad Nacional de Córdoba.

Roitenburd, S. (2000). Nacionalismo católico. Córdoba (1862-1943). Educación en los dogmas para un proyecto global restrictivo. Córdoba, Argentina: Ferreyra.

Rokkan, S. (1971). Nation-building, Cleavages Formation and the Structure of Mass Politics. Oslo, Noruega: Universitaetsvorlaget.

Servetto, A. (1998). De la Córdoba combativa a la Córdoba militarizada 1973-1976. Córdoba, Argentina: Ferreyra.

Tcach, C. (1999). Amadeo Sabattini: la nación y la isla. Buenos Aires, Argentina: Fondo de Cultura Económica.

Tcach, C. (2010). Retrato político de la Córdoba de los treinta en Tcach, C. (Coord.). Córdoba bicentenaria. Claves de su historia contemporánea, 193-224. Córdoba, Argentina: Universidad Nacional de Córdoba.

Tcach, C. (2017). Ni laica ni mixta ni curiosidad malsana: la educación en Córdoba entre generales y almirantes (1943-1944). Coordenadas. Revista de Historia Local y Regional, (8), 21-35.

Zanatta, L. (1999). Perón y el mito de la Nación católica. Iglesia y Ejército en los origenes del peronismo (1943-1946). Buenos Aires, Argentina: Sudamericana.

Zanatta, L. (2005 [1996]). Del Estado liberal a la Nación católica. Iglesia y Ejército en los orígenes del peronismo. 1930-1943. Bernal, Argentina: Universidad Nacional de Quilmes. 